\section{Refereed papers}

\section{A comparison of UK academics' conceptions of information literacy in two disciplines: English and Marketing}

\author{
Sheila Webber, Stuart Boon, \\ Bill Johnston
}

\begin{abstract}
Authors
Sheila Webber is Senior Lecturer in the Department of Information Studies, University of Sheffield.

Stuart Boon is a Lecturer in the Centre for Academic Practice and Learning Enhancement, University of Strathclyde, Glasgow (formerly Research Associate at the University of Sheffield)
\end{abstract}

Bill Johnston is Senior Lecturer in the Centre for Academic Practice and Learning Enhancement, University of Strathclyde, Glasgow.

Email:s.webber@sheffield.ac.uk

\begin{abstract}
The authors aim to present and compare findings from a phenomenographic investigation into conceptions of information literacy in two populations: academics in English and Marketing disciplines teaching at British universities. These were chosen as examples of, respectively, soft-pure and soft-applied disciplines. We begin by defining information literacy and briefly setting our research in context. We explain the nature of research using the phenomenographic approach, and describe our sample and methods. We present firstly, the four qualitatively different conceptions of information literacy held by the English academics, and then the seven conceptions held by the Marketing academics. Key differences between the conceptions held in the two disciplines are discussed, in particular relating differences to characteristics of soft-pure and soft-applied disciplines. The authors conclude that study of the differences between the conceptions held by the two disciplinary groups can illuminate and guide information literacy initiatives.
\end{abstract}

\section{Acknowledgement}

The authors acknowledge the support of the Arts and Humanities Research Council in funding this project.

\section{Introduction}

This paper summarises and discusses results from an investigation into UK academics' conceptions of information literacy in two disciplines: Marketing and English. This is part of a larger study into the conceptions of academics in four disciplines. We have defined Information Literacy as:

the adoption of appropriate information behaviour to identify, through whatever channel or medium, information well fitted to information needs, leading to wise and ethical use of information in society.

(Johnston and Webber, 2004, 13)

As we have noted (Johnston and Webber, 2003), although there is a considerable literature on information literacy, it is primarily written by librarians. The standards and models for information literacy (e.g. SCONUL Task Force on Information Skills, 1999) which are put forward as frameworks for teaching information literacy have also been developed by librarians. Our research aims to illuminate the issue of information literacy as a subject taught in UK universities, by focusing on the academics' perspective. There has been no large-scale study of UK academics' conceptions of information literacy, nor of their conceptions of pedagogy for information literacy. Previous studies have tended to investigate academics' information seeking behaviour, rather than probing their conceptions of information literacy. In particular recent studies have tended to focus on academics' use of electronic resources (e.g. Talja and Maula, 2003; Ellis and Oldman, 2005; MacKenzie et al, 2005).

\section{Methodology}

Johnston and Webber were awarded funding of $£ 130,000$ by the Arts \& Humanities Research Council (AHRC) for a three year project (November 2002- October 2005). The key research questions are:

- What conceptions of information literacy are held by UK academics?

- What are academics' conceptions and reported practice in educating students for information literacy? 
- Do differences in conception correspond to differences in discipline?

The core part of the project uses the phenomenographic approach to investigate the academics' conceptions. Phenomenography is a qualitative approach, which has been most used in educational research (Marton and Booth, 1997). It was appropriate for this study because of its focus on variation (as opposed to commonality) in conception. This approach has also been used in numerous investigations into conceptions of teaching held by academics (see e.g. Trigwell et al., 1994), in the study by Bruce (1997) of Australian university staff's conceptions of information literacy, and in the study by McMahon and Bruce (2002) into information literacy needs of local staff in crosscultural development projects.

Phenomenographic investigations into students' conceptions of information literacy include Lupton (2004).

Marton describes phenomenography as:

The empirical study of the differing ways in which people experience, perceive, apprehend, understand, conceptualise various phenomena in and aspects of the world around us.

(Marton 1994, 4425.)

As Figure 1 indicates, the investigator is not concentrating centrally on the phenomenon (in our case, information literacy and the teaching of information literacy) nor on the interviewee (in our case, the academic). Instead, the investigator aims to get a picture of how the interviewee conceives of, or experiences, the phenomenon.

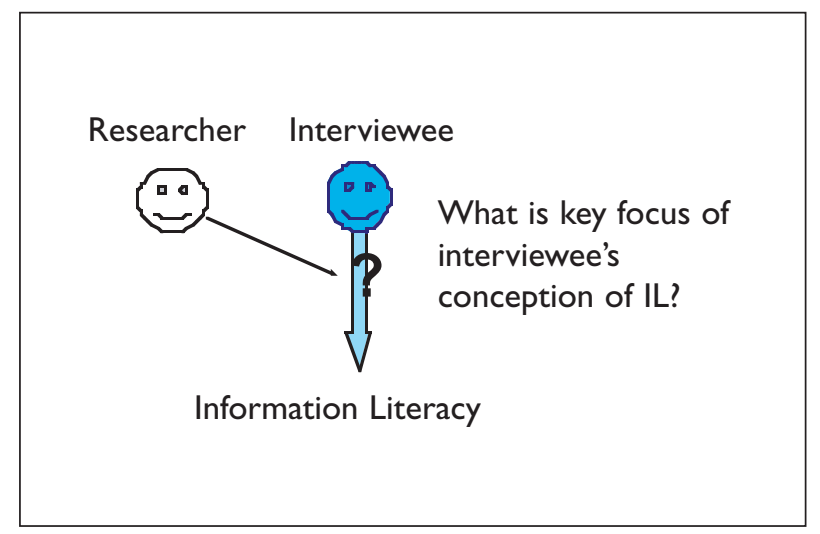

Figure 1: The nature of the investigation
In the interview process it is important that the investigator puts to one side, or "brackets" (Ashworth and Lucas, 2000), their preconceptions about the phenomenon under investigation, so as not to influence the interviewee. Thus in our own investigation we designed open questions which did not point to a particular answer (e.g. asking "what is your conception of information literacy" rather than "do you think that $\mathrm{X}$ is part of information literacy"). The interviewer (Boon) also stoutly resisted invitations from the interviewee to express Boon's own views, and Boon also gently refused requests to pass judgment on the responses supplied by the interviewees.

A further characteristic of phenomenography is that, when analysing the data, the investigator does not focus on the individual, but rather pools all the data collected (in our case, transcriptions of individual interviews) and analyses it as a whole (as indicated in Figure 2).

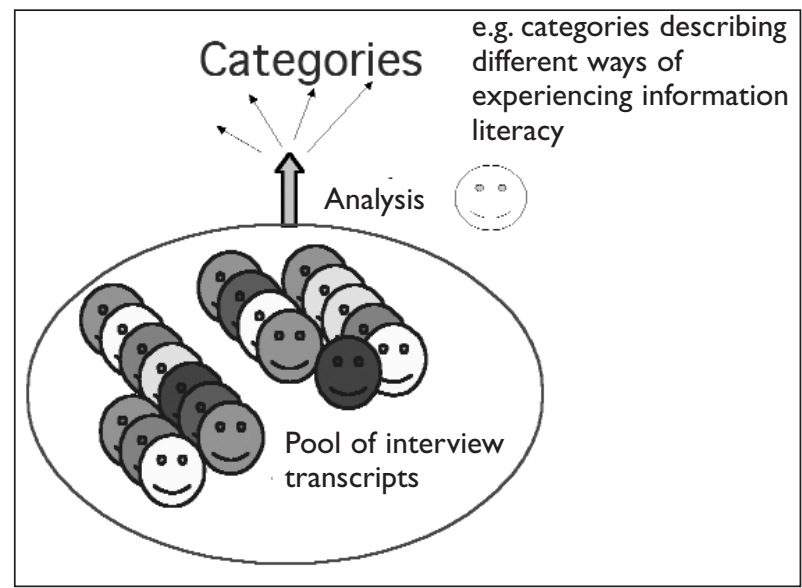

Figure 2: From transcript pool to analysis

The investigator identifies categories describing the different ways of experiencing the phenomenon, seeking in particular the elements that are in "focal awareness" (i.e. centrally important) for each category. The investigator draws on the data inductively to build "categories of description", which describe each qualitatively different conception of the phenomenon (Entwistle and Marton, 1984, 226). Each category will have a different aspect in focal awareness. It is possible that an individual interviewee might hold more than one conception of the phenomenon, since one is 
aiming to identify variation "regardless of whether the differences are between individuals or within individuals" (Marton and Booth, 1997, 124).

The three investigators in this study (Boon, Johnston and Webber) analysed the transcripts collaboratively. This involved each investigator reading the transcripts on their own and recording their impressions of emergent key themes and significant quotations. Different methods were used to record these impressions including the taking of notes, highlighting of passages, and annotation of the transcripts, as well as the creation of diagrams and mindmaps. The three investigators then compared and debated their perceptions of what was emerging from the data during face-to-face discussion. This process started as soon as the first batch of transcripts was completed, with meetings to discuss a mixed-discipline batch of transcripts taking place roughly once every two months.

Once all the interviews had been transcribed, a second phase of analysis began, in which the transcripts were analysed by discipline, in the following order: Marketing, English, Civil Engineering, and Chemistry. In this phase, the qualitative text analysis software Atlas/ti was used to code or mark up each disciplinary "pool" of transcripts to identify key factors and themes. The investigators drew on notes made in the first phase of analysis to drawing up a list of thematic codes, and these codes were refined through an iterative process. This coding process illuminated the data, helping to further identify key quotations and test the extent of agreement between the three investigators concerning the significance of key quotations. In phenomenography, quotations are an integral part of the categories of description and are

not just presented as interesting comments introduced almost incidentally, [but rather] they exemplify the defining features of the categories identified.

(Entwistle and Marton, 1984, 226)

For each discipline, one of the investigators took the lead in drawing the analysis to a close, and proposing the key factors in variation of conception, and the categories of description.
These descriptions provide a snapshot of a particular population at a particular time: in our case academics in the UK in 2003/4. The snapshot presents a holistic view of their experiences, since the phenomenographic approach should illuminate all variations in experience in the given population.

For this study, 20 academics were interviewed in each of our four disciplines. We used Biglan's typology of disciplines (as amended by Becher, 1989) which divides them into hard and soft, and pure and applied. Within this typology, the disciplines we chose were: Chemistry (hard pure discipline), Civil engineering (hard applied); English (soft pure) and Marketing (soft applied). Since the latter two disciplines are the subject of this article, we highlight here some key aspects of soft disciplines as identified by Becher (1989) and Becher and Trowler (2001). One of the characteristics of a soft discipline is that there tends to be less consensus as regards what constitutes an authentic and important contribution to knowledge, and it is also less clear what are the next important research questions (in contrast to hard disciplines, in which there is greater consensus). For both soft pure and soft applied disciplines, new knowledge may consist of interpretations (rather than "discoveries") which provide new insights. However, within an applied discipline the aim of research may be explicitly focused on enhancing personal and social life, and the outcomes often include procedures or protocols which are judged in pragmatic terms.

In our project, we sought a purposive, heterogeneous sample, in which we aimed to include variation in factors which might affect the academics' conceptions of information literacy and their approach to teaching it. These factors included gender, age, type of university and type of department. In the whole sample of 80 people, the academics came from $26 \mathrm{UK}$ universities. Key characteristics for the English and Marketing samples are shown in Table 1. 


\begin{tabular}{|l|l|l|}
\hline & Marketing & English \\
\hline Gender & 8 female, 12 male & 11 female, 9 male \\
\hline Ages ranging between & $21-30$ to 51-60 years & $21-30$ to 61+ years \\
\hline $\begin{array}{l}\text { Years of teaching ranging } \\
\text { between }\end{array}$ & $0-5$ to 26-30 years & $0-5$ to 31+ years \\
\hline $\begin{array}{l}\text { Research quality of Department } \\
\text { (RAE rating in 2001 exercise) }\end{array}$ & 2 to $5^{*}$ & 3 a to $5^{*}$ \\
\hline $\begin{array}{l}\text { Teaching quality of Department } \\
\text { (score in last subject review) }\end{array}$ & Satisfactory to Excellent & Satisfactory to Excellent \\
\hline $\begin{array}{l}\text { Type of university } \\
\text { 4 post- 1992 and 8 pre-1992 } \\
\text { (i.e. 12 different universities) }\end{array}$ & $\begin{array}{l}\text { 5 post-1992 and } 8 \text { pre-1992 } \\
\text { (i.e. 13 different universities) }\end{array}$ \\
\hline
\end{tabular}

Table 1: Characteristics of the Marketing and English samples

Participants were recruited partly by asking librarians to identify potential interviewees (both academics with an active relationship with the library, and academics who had little contact with the library). However, the larger number of academics was recruited by targeting specific academics and departments (e.g. academics in departments with low Research Assessment Exercise (RAE) ratings; female academics at pre-1992 institutions) in order to produce a sufficiently varied sample. The interviews were carried out and recorded by Boon between March 2003 and February 2004, and transcribed verbatim.

The interviews averaged 45 minutes each and were based around three fundamental questions:

- What is your conception of IL?

- How do you engage your students in IL?

- What is your conception of the Information Literate University?

The first two questions elicited reflections and descriptions of the interviewee's behaviour and practice. The third question encouraged interviewees to think beyond the day-to-day constraints and reveal their aspirations and hopes regarding information literacy, as well as giving further opportunities for the interviewees to reflect upon and identify what was most central to them about information literacy and its teaching. Webber and Johnston (2004) have described their own conception of the Information Literate university and outlined some views expressed in this section of the interview by academics.
Each main question had a number of follow-up questions (e.g., for the second question, asking whether the students' information literacy was assessed and what the desired outcomes were for the students' learning). For each discipline, analysis was carried out to identify both conceptions of information literacy and conceptions of pedagogy for information literacy. We will first describe the conceptions of the English academics and then of the Marketing academics. We will then compare their conceptions of information literacy.

\section{Results}

\section{Conceptions of information literacy: English}

Four qualitatively different conceptions of information literacy were identified through the analysis process:

- Accessing and retrieving textual information

- Using IT to access and retrieve information

- Possessing basic research skills and knowing how and when to use them

- Becoming confident, autonomous learners and critical thinkers

The key factors in variation of conception, in focal awareness for the interviewees, were:

1. The particular context within which information literacy was perceived; for example, whether the conception was confined to a particular English course, whether the conception broadened to encompass a number of courses or an entire discipline, or 
alternatively whether it was seen as extending beyond the educational context altogether;

2. The time period in which information literacy was perceived to be needed, useful or otherwise significant; for example, whether the conception was confined to a particular period of study or alternatively whether it was seen as being significant for their entire life;

3. The particular media with which information literacy is associated; for example, whether the conception was confined to a particular medium (e.g. print resources) or alternatively whether it was perceived as extending to cover all media.

Table 2 shows the relationship between the four conceptions of information literacy, in terms of variation in these three key factors. Table 2 thus forms the "outcome space", the "complex of categories of description comprising distinct groupings of aspects of the phenomenon and the relationships between them" (Marton and Booth, 1997, 125) which is key part of the results of a phenomenographic enquiry.

\begin{tabular}{|c|c|c|c|}
\hline $\begin{array}{l}\text { Information literacy } \\
\text { as... }\end{array}$ & Contextual focus & Temporal focus & Media focus \\
\hline $\begin{array}{l}\text { Accessing and } \\
\text { retrieving } \\
\text { information }\end{array}$ & $\begin{array}{l}\text { Particular research } \\
\text { need (e.g. student } \\
\text { essay or academic } \\
\text { writing an article) }\end{array}$ & Immediate need & $\begin{array}{l}\text { Traditional (primarily } \\
\text { print) }\end{array}$ \\
\hline $\begin{array}{l}\text { Using IT to access } \\
\text { and retrieve } \\
\text { information }\end{array}$ & $\begin{array}{l}\text { Particular research } \\
\text { need }\end{array}$ & Immediate need & $\begin{array}{l}\text { Non-traditional } \\
\text { (primarily electronic: } \\
\text { online materials, } \\
\text { multimedia, television } \\
\text { etc.) }\end{array}$ \\
\hline $\begin{array}{l}\text { Possessing basic skills } \\
\text { and knowing how } \\
\text { and when to use them }\end{array}$ & $\begin{array}{l}\text { University and/or } \\
\text { "real world" context }\end{array}$ & $\begin{array}{l}\text { Students: through } \\
\text { course of study } \\
\text { and/or careers } \\
\text { Staff: career skills for } \\
\text { teaching and research }\end{array}$ & $\begin{array}{l}\text { Traditional, with } \\
\text { limited non-traditional } \\
\text { (often confined to } \\
\text { "library skills") }\end{array}$ \\
\hline $\begin{array}{l}\text { Becoming confident } \\
\text { and autonomous } \\
\text { learners and critical } \\
\text { thinkers }\end{array}$ & $\begin{array}{l}\text { Wider information } \\
\text { society context }\end{array}$ & Needed through life & $\begin{array}{l}\text { Traditional and non- } \\
\text { traditional }\end{array}$ \\
\hline
\end{tabular}

Table 2: English academics' conceptions of information literacy: Outcome Space

The following descriptions illuminate the focus and features of each conception. The interviewees are identified by a number between 01 and 20 (e.g. English 05).

\section{Accessing and retrieving textual information}

The focus is on being able to access and retrieve textual information quickly and easily, most often printed matter. This may be secondary critical information, or sometimes the primary text itself.
I am like an old train going along the same rails as far as the word and my concept of information, but yes, that's what it means to me, things that I access through print....

(English 11)

The use and manipulation of the acquired information is often described in disciplinary terms (e.g. close reading) and differentiated from information literacy. 
[Information literacy is being] literate with the use of information, retrieval of information... I guess this is me thinking about information literacy in terms of retrieval skills rather than necessarily the kind of consequent use of information, to be literate with information...

(English 05)

The contextual focus is clearly represented in interviewees' statements as a particular research need. When academics talk about students' information literacy, the contextual focus is on the current course of study. This is closely related to the temporal focus which shows that the information being gathered is for immediate use and, in the case of students, usually tied to an assignment or essay given in a particular class or course.

\section{Using IT to access and retrieve information}

The focus here is on being able to use information technology (IT) to access and retrieve information quickly and easily. Unlike the former conception where the information intended for acquisition was primarily textual, here the information accessed is both textual and non-textual, and encountered in a nontraditional media: online materials, including Departmental websites and the World Wide Web), multimedia and hypermedia, and other electronically recorded materials (e.g. recorded television broadcasts).

[Information literacy] would be the ability to confidently kind of engage with and organise and analyse and manipulate online information and texts, I suppose.

(English 13)

As with the 'Accessing and retrieving textual information' conception, the contextual and temporal foci applied to using IT to find information highlight the need to fulfil the information requirements of a current project, assignment or course.

\section{Possessing basic research skills and knowing how and when to use them}

The focus of this conception of information literacy is on possessing a set of basic research skills and being able to use and apply those skills when required (e.g. in writing an essay, constructing a presentation, producing material for a dissertation). For the academics, these skills are essential to them as teachers and researchers, and they position themselves as already having these skills. In the interviews the emphasis is on developing a set of research skills in students of English, which will be of use not only in the current English course, but also throughout the students' three- or four-year course of study.

These basic research skills are often likened to, or described as, 'bibliographic skills, 'research methods' or 'library skills'.

...being able to handle bibliographies, being able to use a library effectively and efficiently, um, and pursue references, both being able to present a reference correctly and also being able to follow a reference through... a pool of resources they could go back to....

(English 08)

The contextual focus is not solely trained on the current course of study, but is much broader, encompassing the students' entire academic career and often extending to their lives outside the university. Likewise, the temporal focus is on students' long-term information needs, rather than the immediate needs required by an assignment or particular class or course.

\section{Becoming confident, autonomous learners and critical thinkers}

The focus here is on personal growth and development and the acquisition of higher order information skills in order to become confident autonomous learners and critical thinkers. The conceptions are equally applied to students and staff. A greater emphasis is placed on critical analysis, questioning processes and evaluating results, and developing understanding, selfawareness and self-sufficiency. Attention is largely on the individual and the individual's role in, and engagement with, the wider information society. The emphasis is not on achieving success in one's career, but rather on successfully becoming an information literate citizen.

Um, it implies to me, I mean to me information literacy is a part of civic engagement and civic participation, um, without even at least even a passing understanding of how information is produced, how it is constructed, how it's 
presented, um, how it is - if one can say thisintended to be understood and interpreted, then one cannot make sense of the world.

(English 06)

In addition to developing much needed skills and abilities in acquiring, manipulating, and using information, students must develop a level of awareness, confidence and self-efficacy relating to those skills and abilities. Selfreliance, self-efficacy, independence of thought and confidence were also required of every academic. Becoming confident autonomous learners and critical thinkers was clearly a goal for both students and staff.

\section{Conceptions of information literacy: Marketing academics}

Six conceptions of information literacy were identified:
1. Accessing information quickly and easily to be aware of what's going on;

2. Using IT to work with information;

3. Possessing a set of information skills and applying them to the task in hand;

4. Using information literacy to solve real-world problems;

5. Becoming a critical thinker;

6. Becoming a confident, independent practitioner.

The key factors in variation were:

1. The locus for development or activity, and;

2. The form of engagement with information.

Table 3 shows the outcome space for the Marketing academics, illustrating the variations and the relationship between the conceptions.

\begin{tabular}{|l|l|l|}
\hline Information literacy as ... & $\begin{array}{l}\text { Locus for development or } \\
\text { activity }\end{array}$ & $\begin{array}{l}\text { Form of engagement with } \\
\text { information }\end{array}$ \\
\hline $\begin{array}{l}\text { Accessing information } \\
\text { quickly and easily }\end{array}$ & Outside world & Information sources \\
\hline $\begin{array}{l}\text { Using IT to work with } \\
\text { information }\end{array}$ & $\begin{array}{l}\text { Specific context in which } \\
\text { person/task is situated }\end{array}$ & $\begin{array}{l}\text { Tools applied to the } \\
\text { information }\end{array}$ \\
\hline $\begin{array}{l}\text { Possessing a set of } \\
\text { information skills and } \\
\text { applying them to the } \\
\text { task in hand }\end{array}$ & $\begin{array}{l}\text { Specific context in which } \\
\text { person/task is situated }\end{array}$ & Skills applied to the information \\
\hline $\begin{array}{l}\text { Using information } \\
\text { literacy to solve } \\
\text { real-world problems }\end{array}$ & $\begin{array}{l}\text { Specific context in which } \\
\text { person/task is situated }+ \\
\text { Outside world }\end{array}$ & $\begin{array}{l}\text { Meaning explored within/from } \\
\text { the information }\end{array}$ \\
\hline Becoming a critical thinker & Internal being or development & $\begin{array}{l}\text { Meaning explored within/from } \\
\text { the information }\end{array}$ \\
\hline $\begin{array}{l}\text { Becoming a confident, } \\
\text { independent practitioner }\end{array}$ & $\begin{array}{l}\text { Internal being or development } \\
+ \text { Outside world }\end{array}$ & $\begin{array}{l}\text { Meaning explored within/from } \\
\text { the information + Skills applied } \\
\text { to the information }\end{array}$ \\
\hline
\end{tabular}

Table 3: Marketing academics' conceptions of information literacy: Outcome Space

Again, the key characteristics of each of these conceptions will be described. The interviewees are identified by a number between 01 and 20 (e.g. Marketing 05)

\section{Accessing information quickly and easily to be aware of what's going on}

The focus is on being able to get access to a wide variety of information quickly and easily. The key purpose is keeping in touch with, and drawing on, what is going on in the outside world (quotations relating to this aspect will be given in the Discussion section of this paper). Skills in using and presenting information are also important, as is an ability to evaluate what you have found, but the focus is on awareness 
of, access to and gathering of information.

Information presents us with a challenge, a growing challenge, on almost a daily basis. So being able to deal with information is a significant need. And, for me, it begins with the ability to access it, to get it in your hands.

(Marketing 20)

\section{Using IT to work with information}

The focus here is on using information technology (IT) tools efficiently and effectively to work with information. Software applications, such as SPSS, and communications networks are emphasised, rather than hardware. Using, presenting and finding the information are mentioned, but the central focus is on the use of IT tools in a specific context.

Information that is electronically stored, whether it's via the internet or part of these databases, and... and, well, information technology. The means of gathering it, and analysing it, and doing things with it would move into the packages like Access or SPSS. So it would be the sources of it and then what you could do with it, how you could play around with it.

(Marketing 02)

The ability to manipulate numeric as well as textual data is important in this conception.

\section{Possessing a set of information skills and applying them to the task in hand}

The focus is on developing a set of information skills and being able to apply the relevant skills to a particular task (e.g. writing an article, producing an assignment). There may be explicit articulation of a process, but the emphasis is on developing individual skills within that process, rather than developing a holistic concept of the process itself.

[in response to "what is your conception of information literacy?'] Sift, sort and analyse! Definitely! [Laughs.] No... well, yes, actually, but with students who know how to find information and to disseminate. So, find, sift, sort, analyse and disseminate. There! Just like that. Brilliant.

(Marketing 05)
A number of skills are mentioned. The exact terms used by participants differ, but skills in accessing, selecting, working with and disseminating information are present with this conception of information literacy. There may be slightly more discussion of one aspect than another, but no one skill is the focal point.

\section{Using information literacy to solve real- world problems}

Category four focuses on understanding a problem and understanding how information can be used to solve the problem. It is qualitatively different from conception three, in that the central focus is on the problem, and working with information in relation to the problem, rather than on skills. Even when talking in an academic context, the problem may be identified as being connected to the "real world".

I suppose it [information literacy] is the means by which you learn the skills you need to be able to answer a problem. It is being able to look at a problem, to have the skills to find the information you need to answer the problem, and then to answer it.

(Marketing 01)

\section{Becoming critical thinkers}

The central focus is on becoming a critical thinker. Most important to this development are higher order information skills such as understanding and interpreting information. Accessing the information is also important, but with an emphasis on applying critical thinking to this process of finding and selecting information. There is awareness of the application of the information, and the world in which it is used (since the critical thinking takes place in a context), but the central focus is on personal development of critical thinking.

No, right, let's see, information literacy is... [pause]... is learning to become an independent critical thinker who... who can understand what's given to them and how to deal with it...maybe?

(Marketing 15)

Understanding, meaning and the personal development of a questioning approach are emphasised for both students and academics: 
Refereed paper

Sheila Webber, Stuart Boon, Bill Johnston

[Interviewee, talking about his/her own information literacy] And always questioning. Thinking about who the author is: is he reputable or not? Is the article scholarly? Is it peer-reviewed? Who is behind it? Always thinking, always questioning.

Interviewer: So that's similar to what you want your students to do.

Interviewee: Oh, yeah, it's the exact same thing, really. I want them to be thinkers and questioners. If they are not then, then, uh... then they are wasting everyone's time. Go be a car salesman. If you want the easy way out, go sell mobile phones! [Laughs.]

(Marketing 11)

\section{Becoming a confident, independent practitioner}

The focus is on the use of information literacy as an important part of becoming a confident practitioner. Thus there is a focus on personal development to become this practitioner, who will have to make sense of information and apply skills in a real world context.

It [information literacy skills] means I can do my job. Do it effectively. I can find the information I am looking for and I know what to do with it as well.

(Marketing 15)

... hmm, what do they get out of it [information literacy instruction]? [Long pause.] I think confidence is important and, even... just experience and practice. It's important that they know they do research, that it's not scary as you said, and that it is a skill they can do.

(Marketing 15)

It is not just the competence in information literacy that is important here, it is awareness of that competence as a positive part of your practice.

\section{Comparison of English and Marketing findings}

Both samples of academics have a conception focusing on information sources, and another focusing on using IT. However, there are differences between these similar conceptions. Differences correlate with varying ideas of what "information" is, and differences in the extent to which the outside world is important. In terms of information sources, with the English academics there is an emphasis on the text (particularly books). This correlates with previous research that has identified that humanities scholars still prize the text. For example, Talja and Maula (2003, 680), in their study of use of electronic sources, note that for English academics the sources "most important for their research are usually books", or as Ellis and Oldman $(2005,35)$ note, in their study of English literature academics' use of the internet: "Many [academics] also stressed the necessity to feel the real object of their academic activities: the printed book".

In contrast, a variety of sources (e.g. news, market reports, journals, numerical datasets, company websites, organisations and people, including observation of people in real-life situations) is mentioned by all marketing academics in our study. Electronic sources were an accepted part of this mix for marketing academics, whereas, as is evident from the categories described above, a focus on either traditional or electronic sources was a key factor in English academics' conception of information literacy. The English academics' greater emphasis "library skills" or "bibliographic skills" reflects a more frequent engagement with types of information source that are still typically found within a physical library. One may note here the findings in a UK study (Stubley and Kidd, 2002), which found that far more Arts \& Humanities academics (67\%) than social science and science academics (18-19\%) used library catalogues outside their institutions. More emphatically than their English colleagues, some Marketing academics openly stated their relief that the move to electronic access had freed them from using the library: "I've always had a personal reluctance to going to the library and accessing things" (Marketing 07).

The 'Real World' emerges as a key factor in some of the conceptions of information literacy for Marketing academics (notably in the Sources, Problem Solving, and Confident Practitioner conceptions). Some Marketing 
interviewees referred to their work outside the university, as part of their explanation of why information was important to them:

We deal with a dynamic reality here, and you've got to some how explain it by resorting to recent examples and analysing data, and I can't dissociate my professional life from my personal life because I also write in newspapers and scientific newspapers, so it's... yeah, it's crucial.

(Marketing 07)

For my own research, I have to gather a lot of information on different companies, say, so that means using papers, internet resources, contacts I have in the business world, and often conversations. [...] Information is very significant to my profession. Being able to find information quickly and easily is very, very important. Then to be able to use the information, to apply it and make it work for you, or your client. Consultancy is all about gathering and manipulating information.

(Marketing 09)

This is not just a factor for academics;

Marketing 09 is also clear that "Information will play a role in their [students'] careers." This is in contrast to the English academics' conceptions, where there is a greater focus on personal development as a critical being, in the academic world, or in a social context:

The aims and goals [of an Information Literate University]. To contribute to the wider society, through its information, through its research, through its advancement of human understanding and knowledge. Even if that human understanding and knowledge does not bring any commercial benefits, or especially if it doesn't.

(English 08)

The relationship with the world of work outside academia is more ambivalent than for the Marketing academics:

It's understood and hoped that they would achieve that [acquire skills], before sort of setting them free to go out into the big, bad world, and use their new skills...

(English 01)

Whilst English academics with a Possessing Basic Research Skills conception of information literacy stressed the value to future life of transferable skills learnt as part of an English degree, the tone is less bullish than that of Marketing lecturers:

I mean, those are the kind of [transferable] skills which, if you want to talk about vocational skills in English, then those are the things that you are reduced to say, and I think they are valuable skills.

(English 10)

This difference between English and Marketing academics' conceptions correlates with the difference between a pure discipline (English) an applied discipline (Marketing), noted earlier within this article. Becher and Trowler summarise observations on pure vs. applied disciplines in noting:

that pure knowledge, though increasingly vulnerable to epistemic drift, is essentially selfregulating, and that applied knowledge, though occasionally prone to academic drift, is in its nature open to external influence.

(Becher and Trowler, 2001, 185)

Becher and Trowler identify technical and social professions being "in part beholden" (169) to the vocational groups they are linked with, and also influenced by Government and commercial agenda. The "applied" aspect of marketing is clearly identified by our interviewees, both in terms of input and of output, for example:

Marketing is all about looking at information, from consumers and businesses, from governments and from consumer groups. It's all about making sense of data and information, and then using that data to market a product, a company, or an event.

(Marketing 12)

In contrast, Becher and Trowler note a down side for humanities scholars in that:

its comparative freedom from the fetters of government and commerce is won at the expense of a philistine perception that it [humanities research] is marginal and irrelevant as well as small-scale and trivial.

(Becher and Trowler, 2001, 169)

This echoes feelings expressed by some of our interviewees that English is an insular discipline inhabiting a "ghetto" (English 04) and being 
disconnected from the outside world and other disciplines.

One notable difference between the Marketing and English academics' conceptions of information literacy is that exploring the meaning of the information was a key focus in differentiating three of the Marketing academics' conceptions, whereas it did not emerge as the focal differentiating factor in the English academics' conceptions. This was not because the exploration of meaning was not deemed to be important. On the contrary, it was seen as a fundamental part of the discipline of English. Therefore, on the one hand, emphasis on this aspect was not a factor for variation. On the other hand, it was also not specifically associated with information literacy, but rather something that all English students and academics had to develop: an ability to engage critically with a text, or with other artistic expressions.

Those English academics with a Becoming confident autonomous learners and critical thinkers conception did identify critical thinking as key to their conception of information literacy. However, others explicitly claimed sense making aspects and critical analysis as being part of English, not as part of information literacy. These aspects are seen as part of disciplinary learning:

For me I think the absolutely fundamental tool that I think students in English Studies require is close-reading skills, so I tend to do a lot of modelling that for my students.

(English 19)

I mean, in most of my work I don't separate the idea of information literacy from just what it is that I am doing, and in some ways I think that that is healthy and I wouldn't want to separate it out and think, 'These are detachable skills.'

(English 02)

The boundary between information literacy and their own discipline was thus less clear and more troublesome for English academics. By comparison, information and information literacy were seen more straightforwardly as important for those studying, teaching and researching Marketing. We note that this identification of information as an important and separate area of mastery can be seen in standard marketing textbooks, which normally contain sections on information gathering for market data, and, increasingly, information manipulation (e.g. data mining in the context of Customer Relationship Management).

\section{Conclusions}

In starting our investigation, we hypothesised that there could be disciplinary differences in conceptions of information literacy, and comparison of our two phenomenographic analyses seem to support this hypothesis. We intend to engage academics within the disciplines in debate about information literacy, using our research as a focus. Our discoveries about conceptions of information literacy could also, and importantly, be used by librarians to determine how they might work with academics, and to decide what impact librarians want to have on student learning.

The JUSTEIS study (Urquhart et al, 2003), which focused in particular on the UK undergraduate experience, also concluded that "disciplinary differences do matter, and that "quality of information" may be defined in different ways by different disciplines" (p178), noting that varying "user support models" might therefore be needed. We contend that there is scope to develop information literacy teaching, taking variation in academics' conceptions as a key element in reviewing course design.

Some surveys of academics' use (or non-use) of electronic journals, databases or subject gateways have made academics sound like naughty children who are wilfully refusing to use these nice electronic goodies. Rather than trying to measure academics' level of information literacy against some generic standard, it makes more sense for librarians (and sponsoring agencies) to engage with the language and social discourse of the discipline, in order to create more effective working relationships with academics.

It also makes sense for everyone, including librarians, to reflect on their own conceptions of 
information literacy, and be aware of the variety of approaches. It can be noted that some academics have "Higher-order" conceptions of information literacy, for example focusing on critical thinking. These academics might not be enthused by an approach from librarians which described information literacy as a toolbox of skills. Such an academic would probably respond better to a discussion about how he or she could work with the librarian to encourage more critical thinking.

There is evidence in information behaviour research, as well as the authors' own research, that can help understand the nature of information, and information literacy, within different disciplines. Making use of the research evidence may also be useful in opening up a dialogue with academics and stimulating them to reflect on their own practice. An increasingly stressful and demanding academic environment can encourage an "us and them" culture of blame or indifference, rather than empathy. However, empathy and dialogue seem a necessary component in achieving effective partnerships for information literacy education.

\section{References}

Ashworth, P. and Lucas, U. (2000) Achieving empathy and engagement: a practical approach to the design, conduct and reporting of phenomenographic research, Studies in Higher Education, 25(3), 295-308.

Becher, T. (1989) Academic tribes and territories, Milton Keynes, Society of Research into Higher Education.

Becher, T. and Trowler, P.R. (200I) Academic tribes and territories: intellectual enquiry and the culture of disciplines, (2nd ed.) Milton Keynes, Society of Research into Higher Education \& Open University Press.

Bruce, C. (1997) The seven faces of information literacy, Adelaide, Auslib Press.

Ellis, D. and Oldman, H. (2005) The English literature researcher in the age of the internet, Journal of Information Science 3I(I), 29-36.

Entwistle, N. and Marton, F. (I 984). Changing conceptions of learning and research, in F. Marton., D. Hounsell, and N. Entwistle. The experience of learning, Edinburgh, Scottish Academic Press, pp. 2 I I-228.
Johnston, B. and Webber, S. (2003) Information literacy in higher education: a review and case study, Studies in Higher Education, 28(3), 335-352.

Johnston, B. and Webber, S. (2004) The role of LIS faculty in the information literate university: taking over the academy? New Library World, I05(I I 96/ I I 97), I 2-20.

Lupton, M. (2004), The learning connection: information literacy and the student experience, Auslib Press, Adelaide.

MacKenzie, A. et al. (2005) Big Blue Connect. Manchester Metropolitan University. Available at: http://www.library. mmu.ac.uk/bbconnect/ [Accessed II September 2005]

Marton, F. (1994) Phenomenography, in T. Husén and T. N. Postlethwaite. (Eds) The International Encyclopedia of Education. (2 $2^{\text {nd }}$ ed). Vol. 8. Pergamon. pp. 4424 - 4429.

Marton, F and Booth, S. (1997) Learning and awareness, Mahwah, Lawrence Erlbaum.

McMahon, C. and Bruce, C. (2002) Information literacy needs of local staff in cross-cultural development projects, Journal of International Development, I4, I I3- I 27.

SCONUL Task Force on Information Skills. (1999) Information Skills in Higher Education, London, Society of College, National and University Libraries.

Stubley, P. and Kidd,T. (2002) Questionnaire surveys to discover academic staff and library staff perceptions of a national union catalogue, Journal of Documentation, 58(6), 6 I I-648.

Talja, S. and Maula, H. (2003). Reasons for the use and non-use of electronic journals and databases: a domain analytic study in four scholarly disciplines, Journal of Documentation, 59(6), pp. 673-691.

Trigwell, K., Prosser, M. and Taylor, P. (1994) Qualitative differences in approaches to teaching first year university science, Higher Education, 27, 75-84.

Urquhart, C. et al (2003) Uptake and use of electronic information services: trends in UK higher education from the JUSTEIS project, Program, 37(3), 168 - 180.

Webber, S. \& Johnston, B. (2004). Perspectives on the Information Literate University, SCONUL Focus, 33, 33-35. Available at: http://www.sconul.ac.uk/pubs_stats/newsletter/33//2.pdf [Accessed II September 2005] 